\title{
Is our Youth Cycling to Health? Results From the Netherlands' 2016 Report Card on Physical Activity for Children and Youth
}

\author{
Marcella Burghard, Karlijn Knitel, Iris van Oost, Mark S. Tremblay, Tim Takken, \\ and the Dutch Physical Activity Report Card Study Group
}

\begin{abstract}
Background: The Active Healthy Kids the Netherlands (AHKN) Report Card consolidates and translates research and assesses how the Netherlands is being responsible in providing physical activity (PA) opportunities for children and youth ( $<18$ years). The primary aim of this article is to summarize the results of the 2016 AHKN Report Card. Methods: Nine indicators were graded using the Active Healthy Kids Global Alliance report card development process, which includes a synthesis of the best available research, surveillance, policy and practice findings, and expert consensus. Results: Grades assigned were: Overall Physical Activity Levels, D; Organized Sport Participation, B; Active Play, B; Active Transportation, A; Sedentary Behaviors, $C$; Family and Peers, $B$; School, $C$; Community and the Built Environment, $A$; Government Strategies and Investments, INC. Conclusions: Sedentary behavior and overall PA levels are not meeting current guidelines. However, the Dutch youth behaviors in sports, active transportation, and active play are satisfactory. Several modifiable factors of influence might be enhanced to improve these indicators or at least prevent regression. Although Dutch children accumulate a lot of daily PA through cycling, it is not enough to meet the current national PA guidelines of 60 minutes of moderate-to-vigorous PA per day.
\end{abstract}

Keywords: child health, health communication, knowledge translation, exercise, play, public health

Data from the Dutch Organization for Scientific Research (TNO) reveal that the percentage of children and youth meeting the Dutch Norm for Healthy Physical Activity (NNGB; to be at least moderately active for at least 60 minutes a day ${ }^{1}$ ) show a declining trend for the period between 2006 and $2014 .^{2}$ For 4- to 11-year-olds, the number of children who are meeting the NNGB has decreased by approximately $10 \%$ during this period. Further, it seems that the older Dutch children are getting more inactive. For example, there is an increasing trend in the percentage of 12- to 17-year-olds who were inactive (when a child is at least moderately physically active for 60 minutes on 2 days or less ${ }^{2}$ ) in 2010 (11\%) compared with $2014(15 \%) .^{2}$ These numbers suggest a growing inactivity crisis among Dutch children and youth.

It is not totally clear in what type of activity Dutch children accumulate their largest amount of physical activity (PA) during the day, and it is not clear what the best avenues to improve PA levels will be. It could be during active play, physical education (PE), school, organized sports, or active transportation. The Netherlands is known globally for its widespread use of bicycles and some call it a "cycling nation." Indeed, many Dutch inhabitants own a bike and cycle frequently. Numbers show that $84 \%$ of the Dutch inhabitants from age 4 years and older own a bike. Those owners have an average of 1.3 bikes per person. This leads to 18 million bikes in the Netherlands and 13.5 million bike owners. ${ }^{3}$ It seems that the nation itself is perfectly shaped to cycle. There are no large mountains, only a few small hills are present, and every city or village has an extensive layout of cycle paths and routes. In many urban areas separate cycle paths are not uncommon. It could be that the Dutch youth is cycling to health and in this first Dutch Physical Activity Report Card, we aim to provide better insight about the PA levels and patterns of the Dutch youth.

After the global matrix, in which 15 countries were compared, ${ }^{4}$ the idea was born to develop the first Physical Activity Report Card for the Netherlands. In 2014, a group of researchers led by Tim Takken of the Child Development and Exercise Centre at Wilhelmina Children's Hospital obtained a seed grant of the Sport $\&$ Society focus area of the Utrecht University, and the project was launched.

The aim of the present article is to provide an overview of the methods and results of the first Dutch Report Card.

Takken, Burghard, Knitel, and van Oost are with the Child Development \& Exercise Center, \& Shared Utrecht Pediatric Exercise Research (SUPER) Laboratory, Wilhelmina Children's Hospital, University Medical Centre Utrecht, the Netherlands. Tremblay is with the Healthy Active Living and Obesity Research Group Children's Hospital of Eastern Ontario Research Institute, Ottawa, Ontario, Canada. The Dutch Physical Activity Report Card Study Group includes Cindy Veenhof (Utrecht University; HU University), Dick Ettema (Utrecht University), Dirk-Wouter Smits (Utrecht University), Dave van Kann (Maastricht University), Evelyn Monninkhof (University Medical Centre Utrecht), Han Kemper (Institute for Health and Care Research EMGO+), Janke de Groot (Wilhelmina Children's Hospital; HU University), Jan Faber (Secondary Vocational Education Board [MBO Raad]), Jo Lucassen (Mulier Institute; Royal Dutch Society for Physical Education), JanJaap van der Net (Wilhelmina Children's Hospital), Mariëlle Beijersbergen (Utrecht Municipality), Nicolette Schipper-van Veldhoven (Windesheim University of Applied Sciences; Dutch Olympic Committee*Dutch Sports Confederation), Peter Barendse (Knowledge Centre for Sport Netherlands), Remko van den Dool (Mulier Institute), Steven de Vries (Primary School Board [PO-Raad]), Teatske Altenburg (Institute for Health and Care Research EMGO+), and Wanda Wendel-Vos (National Institute for Public Health and the Environment [RIVM]). Takken (t.takken@umcutrecht.nl) is corresponding author. 


\section{Methods}

The Principal Investigator and Project Manager formed a research work group (RWG) together with 6 researchers of the University Medical Centre Utrecht, Utrecht University, and Utrecht University of Applied Sciences. The RWG made a first inventory of the possible data sources by knowledge of available databases and by searches in scientific databases and websites of useful institutes. In addition an inventory for themes and relevant experts and/or organizations was made. Subsequently, an expert group was formed with involvement of RIVM (National Institute for Public Health and Environment), Mulier Institute, Dutch Olympic Committee/Dutch Sport Federation (NOC*NSF), Windesheim University of Applied Sciences, Maastricht University, Knowledge Centre for Sport Netherlands (KCS), and advising roles for the Dutch Society for Physical Education (KVLO), Primary Education Board (PO-Raad), Vocational Education and Training Board (MBO Raad) and municipality of Utrecht (Dept of Public Health). Two research assistants supported the principal investigator and project manager and together they identified data sources, key articles and made an overview of the existing evidence. For the developmental process, guidelines of the Canadian framework were followed. ${ }^{5}$ Both the RWG and the expert group were responsible for the interpretation and evaluation of the data sources and evidence. Selection was mainly based on national representativeness and consecutive measurement years. The RWG and expert group had to define the definitions and adjust the benchmarks of the indicators from the Canadian framework to the Dutch situation. The research evidence was compared against these benchmarks to assign a final grade.

It was decided to only include the required 9 indicators from the Active Healthy Kids Canada framework, no additional indicator was included. ${ }^{5}$ For the evaluation of the indicators, data of the period 2010 up to 2014 has been included. When available, we used data from national surveys conducted by Statistics Netherlands (CBS) and RIVM as primary sources. If these sources could not provide the required data to grade an indicator, data from other (partial) governmental sources were used (eg, TNO, Netherlands Institute for Social Research (SCP), Mulier Institute) or data from nongovernmental organizations (eg, Jantje Beton).

\section{Benchmarks}

For the indicator Overall Physical Activity, the percentage of children meeting the Dutch Physical Activity Guideline was used to grade the indicator. The grading was based on data from the National Health Survey (NHS). The NHS is part of the Lifestyle Monitor, in which data regarding several lifestyle themes are gathered annually. ${ }^{6}$ For Organized Sport Participation, consensus was reached to use data regarding engaging in sports on a weekly basis. In the NHS, respondents were asked their participation in sports in a regular week in the past months and it was assumed that this was representative for sports participation in the entire year. ${ }^{7}$

For Active Transportation it was decided that grading should be based on the percentage of children who use active transportation (walking or cycling) to and from school and/or work, at least 3 times a week. For both indicators, data from the NHS were used. Active Play was assessed by the amount of time that children and youth engaged in unstructured/unorganized active outside play in the last week. Data from TNO Monitor Convenant Healthy Weight $(\mathrm{MCGG})^{8}$ were used. TNO includes a continuous national survey called Accidents and Movement in the Netherlands (OBiN). ${ }^{2} \mathrm{OBiN}$ monitors sports injuries, sports participation, exercise behavior and sedentary behavior. The MCGG used several OBiN questions in an additional module in which determinants of exercise, eating behavior and sports participation were collected in a subsample. ${ }^{8}$ No national survey that incorporated active play was performed in the period 2010 to 2014. Two hours of screen time was used as benchmark to grade Sedentary Behavior, using OBiN data for the grading. The indicator Family and Peers was graded based on multiple studies and findings. Data of the $\mathrm{NHS},{ }^{6} \mathrm{MCGG}^{8}$ regarding family and peers next to data of a Mulier Institute study, in which the central theme was sports participation in children in poverty. ${ }^{9}$ Results of the ENERGY-project were used as well. The aim of the study was to explore differences in weight status and energy balance behaviors according to ethnic background among adolescents across Europe. ${ }^{10}$

The indicator Community and the Built Environment was graded based on national survey data from $\mathrm{CBS}$ and $\mathrm{SCP}^{11}$ called Leisure Time Omnibus (VTO). Three aspects were part of the grade: 1) there are enough sports facilities available in my neighborhood; 2) I have sufficient choice of various sports in my neighborhood; and 3) there are sufficient sidewalks, cycle tracks, or other public areas to be physical active in my neighborhood. In this survey, sports and cultural behavior and participation was the area of research. ${ }^{12}$ The indicator School was divided in grades for Primary School, Secondary School, and Secondary Vocational Education. The grades for the different levels of school were aggregated to generate an overall School grade. For each type of education the grade was based on active school policies, duration of physical education (PE) and the presence of a specialist PE educator. Not all aspects concerning school were integrated in national surveys, thus a combination of data from SCP, Mulier Institute and DSP-group was used. For Secondary Vocational Education, it was decided to follow the national advice of the government and Secondary Vocational Education board: the students have to meet the 5\% norm. This means that $5 \%$ of the contact time (education time minus the internship time) exists of exercise and sport. ${ }^{13}$ This corresponds to 60 minutes of exercise per week, at times that the student does not do his/her internship. ${ }^{13}$

For Government Strategies and Investments, the RWG and experts decided that this indicator could not be graded. There were no clear and well-founded benchmarks or criteria to state that policy is effective or which amount of investments is acceptable. Multiple documents of the government were considered, for example the Educational Agenda for sports, PA and healthy lifestyles in and around school, National nota health policy letter and evaluation reports of the Mulier Institute concerning several policies and programs. For nongovernment, websites and annual reports from several national foundations were considered.

The RWG and experts met to evaluate the evidence for each indicator and discuss the proposed grading. In an earlier meeting it was already determined that data from primary sources were to be used for the grading of the indicators.

The grade for each indicator was based on the percentage of children and youth meeting a defined benchmark: $A$ was $81 \%$ to $100 \%$; $B$ was $61 \%$ to $80 \%$; $C$ was $41 \%$ to $60 \%, D$ was $21 \%$ to $40 \%$; $F$ was $0 \%$ to $20 \%$; INC was incomplete data. This grading system is according to the Canadian Report card framework. ${ }^{5}$ During the grading meeting it was decided not to use the designation of a plus $(+)$ or minus sign (-) next to the grade, because consensus was reached that it was unclear which cut-off points and/or which and how many factors results in a plus or minus sign. 


\section{Results}

The 2016 Dutch Report Card is the first assessment of PA behaviors, setting, and sources of influence and government strategies and investments. The grades are summarized in Table 1.

\section{Overall Physical Activity Levels: D}

The grade for Overall Physical Activity levels was a $D$. For the period 2010 to 2014, an average of $29 \%$ of Dutch 12- to 17-yearolds met the Dutch PA guideline of Healthy Physical Activity (NNGB). ${ }^{14,15}$ So, more than two-thirds of Dutch children were not involved in at least moderate PA for at least 60 minutes a day. The most recent data of 2014 showed that $28 \%$ of the Dutch children met this guideline, showing that this indicator is fairly stable in recent years. Except for 2011, boys did meet the guideline more often than girls (average $33 \%$ boys versus $25 \%$ girls). ${ }^{14,15}$

\section{Organized Sport Participation: B}

Organized Sport Participation was graded a B. In 2012 to 2014, $74 \%$ of the 12 - to 17 -year-old children reported engaging in sport weekly ${ }^{14,15}$ (see Methods for criteria weekly athlete). Sports participation was quite consistent over recent years and there was only a minor difference in sport participation between boys and girls (74\% versus $68 \%$ respectively in 2014). ${ }^{14,15}$ Data of NOC*NSF showed that $31.8 \%$ of the organized sport memberships are from youth $(0$ to 17 years). ${ }^{16}$

\section{Active Play: B}

Active Play was graded a $B$, because $70 \%$ of the Dutch 4- to 11-yearold children reported that they played outside in the past week in the afterschool period. ${ }^{8}$ Data of MCGG was used to grade this indicator. Results of a study in the South of the Netherlands showed that $22 \%$ of 10- to 12-year-old primary school children, reported that they spend for 3 or more hours per day playing outside, and $21 \%$ played 2 to 3 hours per day outside. ${ }^{17}$ These data were self-reported by children. ${ }^{17} \mathrm{~A}$ small study initiated by Jantje Beton (a foundation to promote outdoor play) showed that boys play 'more often outside' than girls (21\% versus $14 \%){ }^{18}$

\section{Table 1 Grades According to Physical Activity Indicator in the Netherlands' 2016 Report Card on Physical Activity for Children and Youth}

\begin{tabular}{lc}
\hline Indicator & Grades \\
\hline Overall Physical Activity Levels & $D$ \\
Organized Sport Participation & $B$ \\
Active Play & $B$ \\
Active Transportation & $A$ \\
Sedentary Behaviors & $C$ \\
Family and Peers & $B$ \\
School & $C$ \\
Community and the Built Environment & $A$ \\
Government Strategies and Investments & $I N C$ \\
\hline
\end{tabular}

Note. The grade boundaries for each indicator are: $A$ is $81 \%$ to $100 \% ; B$ is $61 \%$ to $80 \%$; $C$ is $41 \%$ to $60 \%, D$ is $21 \%$ to $40 \%$; $F$ is $0 \%$ to $20 \%$; INC is Incomplete data.

\section{Active Transportation: $\boldsymbol{A}$}

Active Transportation was graded an $A$, because NHS data showed that $79 \%$ of the 12 - to 17 -year-old children cycled 3 or more days to or from school or work and $17 \%$ of the 12- to 17 -year-old children walked 3 or more days to or from school or work. ${ }^{14,15}$ The median minutes per week for cycling to or from school or work was 150 minutes per week. The duration was the same for the age ranges 12-14 and 15-17 years and no differences were observed between genders. ${ }^{14,15}$

\section{Sedentary Behaviors: C}

Data from the TNO MCGG survey reported that $57 \%$ of 4- to 11-year-old children sit in front of a computer or watch TV less than 2 hours a day. ${ }^{8}$ Therefore, the overall grade for Sedentary Behavior was a $C$. When evaluating the sitting and lying patterns of children during school, 4- to 11-year-olds sit/lie on average of 7.5 hours per day and 12- to 17-year-olds sit/lie even more, 9.9 hours per day. On weekend days children of both age groups sit/lie also a large part of the day (4.2 hours for the youngest and 5.4 hours for the adolescents). ${ }^{2}$

\section{Family and Peers: B}

The overall grade for Family and Peers was a $B$. The indicator grade was based on assembling several findings and some of these findings will be listed here. Research from the Mulier Institute regarding poverty and sports participation in children showed that $88.6 \%$ of the children live in a family with sufficient financial resources to participate in sports and cultural activities. ${ }^{9}$ However, $77 \%$ of children in prosperous families have a sports club membership, compared with only $44 \%$ of the children in poor families. ${ }^{9}$ In total, $53 \%$ of the parents (single or with a partner) met the Dutch PA guideline (to engage in at least 30 minutes of moderate PA for at least 5 days a week ${ }^{1}$ ) in $2014 .{ }^{19}$ For peers and friends of 4- to 11 -year-old children it was found that $57 \%$ exercised very often, while in the older age group, results of TNO MCGG showed that $40 \%$ of the friends exercised very often. ${ }^{8}$ According to parents, $62 \%$ of their 4- to 11-year-old children were stimulated to exercise more by their friends. This was $57 \%$ in the 12 - to 17 -year-old age group. ${ }^{8}$

\section{School: C}

The overall School grade was a $C$. Regarding the policies and infrastructure benchmark, some findings will be listed on which the grade was based. In primary school for example, $79 \%$ of the PE teachers agreed (totally) with the statement that an annual planning for PE is present at their school ${ }^{20}$ and $67 \%$ of the PE specialists indicated that their school works with a student tracking system. ${ }^{20}$ The Mulier Institute assessed several aspects of PE (eg, policy, infrastructure, duration of the lessons) in Secondary School. ${ }^{21}$ Their results showed that $98 \%$ of the section leaders of PE reported the presence of an annual planning for PE, $75 \%$ of the secondary schools collaborated with a sports club and $55 \%$ collaborated with the municipality. ${ }^{21}$ The DSP group monitored on behalf of the Secondary Vocational Education board, Secondary Vocational schools from 2006 to 2014, to assess how exercise and sports were integrated in the curriculum. ${ }^{13}$ Their results showed Secondary Vocational Education schools have integrated sports and exercise in their policies for sectors, clusters and domains and $91 \%$ of these schools have explicit attention for the health themes sports and exercise. ${ }^{13}$ Regarding the benchmark 
of the presence of a PE specialist for the PE lessons, it was shown that in Primary School a PE specialist teacher to provide PE was

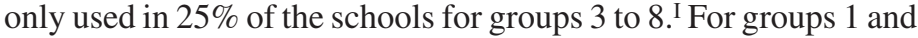
2 , only in $5 \%$ a PE specialist teacher was present. ${ }^{20}$ As dictated by governmental regulations, students in Secondary Schools are taught by a PE specialist teacher. ${ }^{21}$ When Secondary Vocational Educations schools offered PE, in $92 \%$ of these schools a PE specialist provides the PE lessons. ${ }^{13}$

Regarding the duration of the PE lessons, in primary school an average of $48 \%$ of the students received 120 minutes or more PE per week. ${ }^{20}$ Over the years, $85 \%$ of the Secondary School students had $\geq 120$ minutes PE per week. ${ }^{21}$ Of the SVE students, only $12 \%$ met the $5 \%$ policy, ${ }^{13}$

\section{Community and the Built Environment: $\boldsymbol{A}$}

For this indicator, the data of VTO showed that $82 \%$ of $12-$ to 18-year-olds was satisfied with the sports and activity opportunities in their neighborhood. ${ }^{12}$ This percentage is a combination of 3 aspects: 1) there are enough sports facilities available in my neighborhood, 2) I have sufficient choice of various sports in my neighborhood, and 3) there are sufficient sidewalks, cycle tracks, or other public areas to be physical active in my neighborhood ${ }^{12}$ (see methods for more details). Hence, an overall $A$ grade was assigned. A small study initiated by Jantje Beton showed that 6- to 8-year-olds perceived sidewalks and squares in their neighborhood as boring; in addition $46 \%$ of the 9 - to 12 -year-old children agreed with this. ${ }^{18}$

\section{Government Strategies and Investments: INC}

The indicator Government Strategies and Investments was graded as INC due to the absence of clear, well-established criteria of efficacy for this indicator. The Dutch Government strives to offer suitable sport and exercise opportunities, which are safe and accessible. The Ministry of Health, Welfare and Sports funds activities that include: exercise close to home, accessible opportunities, customized and reliable information, and an information infrastructure to help create resilient youth and to make healthy choices easy and stimulate collaborations with the public-private sector. ${ }^{22}$ In this policy, community sport coaches have an important role. Community sport coaches are individuals who operate to increase a connection between sectors as school, community and sport organizations. Their purpose is to create more opportunities for PA and to organize sports activities in neighborhoods. ${ }^{23}$ Many community grants are available (eg, Impulse Community Schools, Sports and Culture). ${ }^{22,23}$

From 2012 to 2016, the Educational Agenda for sports, PA and healthy lifestyles in and around schools was developed by the Ministry of Health Welfare and Sports in collaboration with the Ministry of Education, Culture and Science. School boards and managements were stimulated to conduct their policies according to a 'Healthy School' strategy. For this agenda $€ 4$ million was available for the period of 4 years. ${ }^{23,24}$

In terms of nongovernmental initiatives, several foundations and funding agencies exist. For example, Youth Sports Foundation, funded by the private sector and donations, aims to ensure that children of low socioeconomic status have opportunities to participate in sports and support them in sporting attributes which are needed. ${ }^{23,25}$ Moreover, there are foundations (Johan Cruyff Foundation, Krajicek Foundation, YALP \& Marc Lammers), which offer special playgrounds/sporting fields to promote PA and promote outdoor play opportunities, also in problem areas. ${ }^{26-28}$
In the short overview previously described, it is shown that many (non)governmental programs and initiatives and interventions are present. Unfortunately, in not all programs or initiatives clear goals and indicators are present and consequent monitoring is sometimes lacking. In addition validation of indicators should also be addressed. Therefore, it is currently not possible to give a valid judgment about success or effectiveness for (non)governmental strategies and investments.

Figure 1, illustrates the cover story for the Dutch Report Card on Physical Activity for Children and Youth.

\section{Discussion}

The aim of the present article was to provide an overview of the methods and results of the first Dutch Report Card. The results showed that sedentary behavior and overall PA levels of Dutch youth are not meeting current guidelines. However, behaviors in sports, active transportation and active play are satisfactory.

The Dutch use the bike as a way of transportation, but also for sports and exercise. Bike-use fits well in an active life style and it could be the case that cycling is responsible for a large part of the

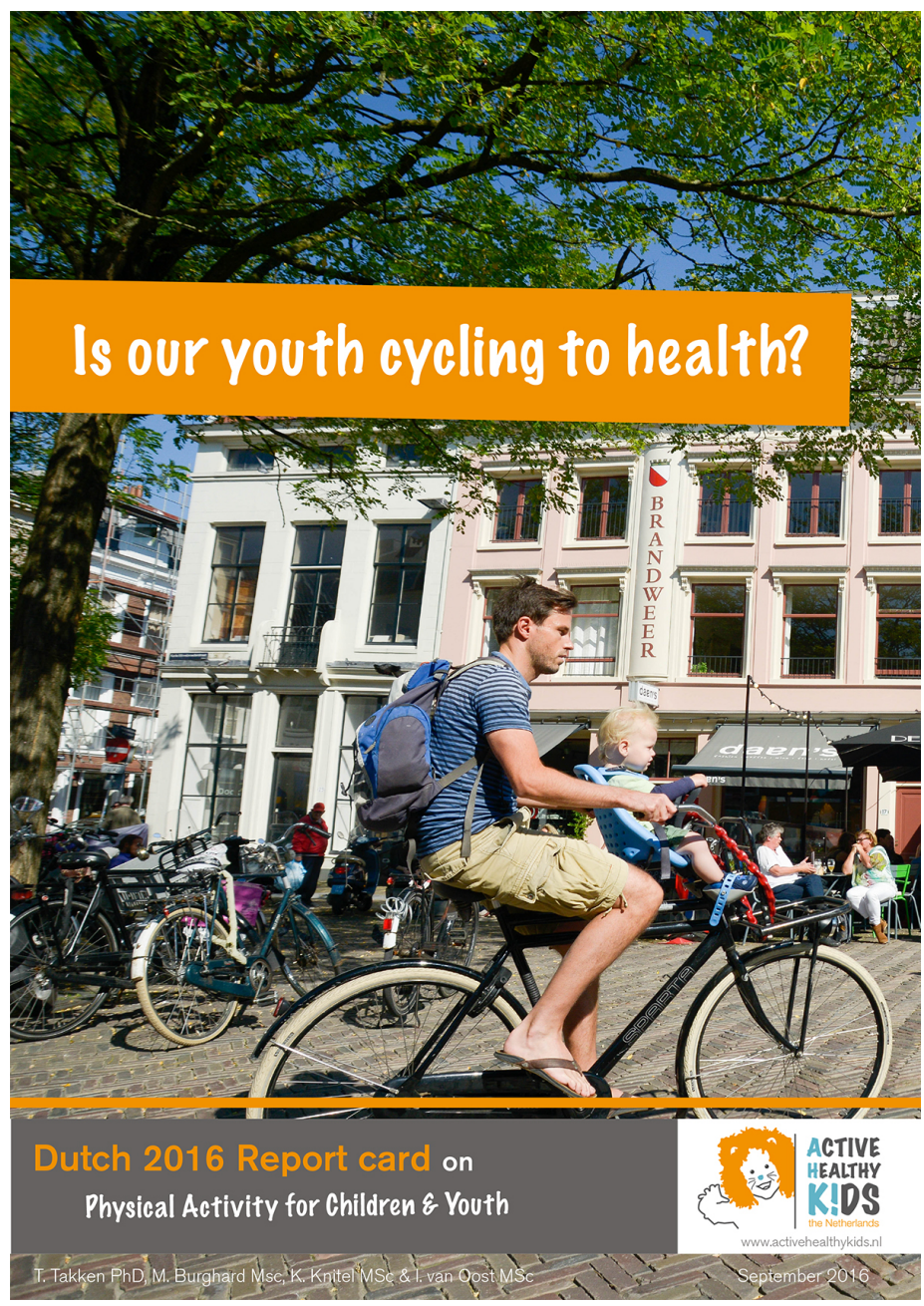

Figure 1 - Front cover of the Netherlands' 2016 Report Card on Physical Activity for Children and Youth. 
daily PA in Dutch youth. It is estimated that Dutch people have on average a 6-month longer life expectancy attributable to bicycle use. ${ }^{29}$ It has been shown that correlations exist between active transport behavior and the attractiveness of the school neighborhood environment, the presence of parks (or trails in parks) and (traffic) safety. ${ }^{30}$ Questions that arise are, can the current built environment still serve the many young cyclists next to the increasingly busy traffic? Is it still safe for children to cycle? Are sports accommodations easy accessible and not too far away from home to use the bicycle? Do the schools have sufficient space to accommodate bike parking? Trends suggest that more parents, because of traffic unsafety, drive their children to and from school even for small distances. ${ }^{31}$ The question is what can convince parents to stop driving their children and instead use the bicycle? Answers to all these questions can provide knowledge about this phenomenon of a bicycling nation and if the Dutch are indeed cycling to health. Therefore, we have the selected the bicycle usage in children as the cover story. Moreover, our results show that many Dutch children use the bike as their way of transportation and it was demonstrated that active transportation is responsible for a large part of school related PA in Dutch youth. ${ }^{32}$

To improve the current situation and to make sure that children will remain using their bikes to go to school or friends, traffic safety and construction of the neighborhood seems important aspects to address.

Even though the overall grading of the community and the built environment is an A, still some children reported that playgrounds are not always easily accessible. They have to cross difficult junctions or busy streets to reach play areas. ${ }^{18}$ Also parents reported that they would not allow their children to cycle by themselves to sports clubs or school because the routes are too dangerous. ${ }^{33}$ Thus, when developing new neighborhoods attention should be drawn to make it more cycle friendly and accessible in which concerns of end users should be incorporated in the design.

The school seems to have an important role in the overall PA patterns of the Dutch children. At school, almost all children can be reached. Schools could attempt to find strategies to make the PE lessons more active and /or that the moderate- to-vigorous active time is more efficient. Research has shown that less than half of the time of the PE lessons is of moderate-to-vigorous intensity in both primary and secondary school. ${ }^{34} \mathrm{Next}$, during PE lessons or during recess, attention should also go to the children who are not already active. Girls are currently a bit neglected in this respect. PE specialists, community coaches or people from sports clubs can all work together to address this. Furthermore, more collaboration between schools, sports clubs and other organizations should be arranged. Sharing facilities will be beneficial for all parties. ${ }^{35}$

Organized sports (concerning sport clubs) has an important role in PA patterns for youth as well. There is a wide range of sports clubs for organized sport. Eighty percent of Dutch children are member of one of the 25,000 local sports clubs, kids having 1 training or more per week and a game a week (competition). Training/coaching is given mostly by volunteers, which makes it questionable if moderate-to-vigorous active time is reached during training. Organized sport could cooperate more with schools, PE teachers and professional trainers in sport.

Finally, the behavior of parents seems to have a great influence on the activity and sedentary behaviors of their children. As the results showed, with a B for family, Dutch parents are not doing it that bad currently. However, despite the fact that the children aren't exercising enough, about a half of the parents don't believe it is necessary for their children to exercise or sport more. ${ }^{8}$ Trends also suggest that more children are brought by car to school and sports. Not all parents are aware that their sports behavior, TV viewing behavior or active transport behavior ${ }^{36}$ is related to the behavior of their children. Consequently, social marketing campaigns, strategies and interventions to increase the knowledge of parents are encouraged and hopefully this will result in more parents who are active with their kids in sport of active play and more parents who cycle together with their children to play grounds or school. If successful, we can maintain the active culture for Dutch youth.

Taking all grades of the indicators into account, it is remarkably that an average of $29 \%$ of the Dutch 12- to 17-year-old youth meets the Dutch PA guidelines, while the grades for nearly all other indicators which contribute to overall PA are higher. Plausible is that the used benchmarks are not distinguishing enough. Duration of an activity (related to the indicators active play, active transportation, organized sport) are currently not included and should perhaps should be incorporated next to frequency. It would be perhaps even better, to include the intensity of the several activity behaviors as well.

For now, we can state that a large amount of the Dutch youth cycle frequently, however it might be that the average duration of a cycle trip is getting shorter. For organized sport for example, it could be that of the activity of a weekly athlete, a minor part exists of at least moderate intensity. When this knowledge is present, the behaviors which contribute to overall PA will be better understand and more evidence-informed and effective strategies and policies can be developed to attack the physical inactivity crisis.

\section{Strengths and Limitations}

This is the first Dutch Report Card that provides a robust overview over a period of 5 years about how the Netherlands is doing, regarding PA opportunities, overall PA levels and the role of sources of influences. Strength of the Dutch Report Card is the many data from nationwide surveys and databases. Furthermore, the participation of many experts and organizations in this area make that all important data sources were identified and included. Unfortunately, not all indicators are integrated in national surveys yet (eg, active play, family and peers, sedentary behaviors). Thus for some indicators, we had to use research with smaller sample sizes and less well representative samples. RIVM has stated that some aspects are integrated already in the 2016 national survey. Hopefully, the other indicators are integrated in future national surveys as well.

The respondents of the national surveys used here (2010-2014) only included 12- to 17-year-old children, thus data of the younger age group are unfortunately lacking. Fortunately, the age group of 4- to 11 -year-olds will be included since the 2016 survey. ${ }^{6}$

For active play, sedentary behavior and government strategies still no established criteria for the definition, measurements and benchmark or its relationship with health exist. As for sedentary behavior, only for screen time guidelines are present but not yet for sitting and lying behavior. All this needs further national and international discussion and consensus

The Health Council of the Netherlands (commissioned by the Minister of Health, Welfare and Sports) evaluates already and if necessary adjusts the current PA and sedentary guidelines based on recent scientific insights. ${ }^{37}$

Self-report and/or parent-report was applied in almost all surveys, however, the (possible) discrepancy for these subjective methods and objective measurements is under discussion. Thus, this needs further scientific exploration as well. 


\section{Conclusion}

This first Dutch Report Card indicates that the sedentary behavior and overall PA levels of the Dutch youth, are not meeting current guidelines. Fortunately, behaviors in sports, active transportation and active play are satisfactory. Several modifiable factors may be targeted to improve these indicators or at least prevent regression. Turning sitting time into nonsedentary time might be a feasible way of improving activity levels of Dutch children. Although Dutch children accumulate a lot of daily PA through cycling, it is not enough to meet the current national PA guidelines of 60 minutes of moderate-to-vigorous PA per day. Cycling is important, however cycling alone is not enough for sufficient levels of PA.

\section{Acknowledgments}

The authors also thank M. Buurman for her contributions to the 2016 Dutch Report Card. Bas van Leeuwen is acknowledged for the design of the Dutch Report Card. This work was supported by a seed grant from the Utrecht University focus area Sport \& Society

\section{Notes}

${ }^{I}$ In the Netherlands, Primary School children from 4 to 12 years of age are taught. There are 8 groups related to age. Group 1 and 2 are similar to kindergarten.

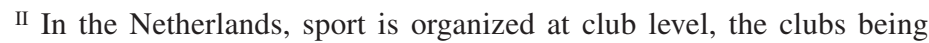
members of a sport federation. Most of these sport federations are in turn affiliated to the National Olympic Committee*Netherlands Sport Confederation (NOC*NSF).

\section{References}

1. Kemper HCG, Ooijendijk WTM, Stiggelbout M. Consensus about the Dutch norm for healthy physical activity. [Consensus over de Nederlandse norm voor gezond bewegen] Tijdschrift voor Gezondheidswetenschappen. 2000;79:180-183.

2. Hildebrandt VH, Bernaards CM, Hofstetter H. Trend Report Exercise and Health 2000/2014. TNO Leiden; 2015. [Trendrapport Bewegen en Gezondheid 2000/2014].

3. Fietsersbond. Cycling in numbers-2. http://www.fietsersbond.nl/defeiten/fietsen-cijfers/fietsen-cijfers-2\#14. Assessed May, 192016

4. Tremblay MS, Gray CE, Akinrove K, et al. Physical activity of children: a global matrix of grades comparing 15 countries. J Phys Act Health. 2014;11(Supp 1):S113-125. doi:10.1123/jpah.2014-0177

5. Colley RC, Brownrigg M, Tremblay MS. A model of knowledge translation in health: the active healthy kids Canada report card on physical activity for children and youth. Health Promot Pract. 13, 3a20-330. 2012 doi:10.1177/1524839911432929

6. National Institute for Public Health and the Environment. Health Survey [Leefstijlmonitor]. http://www.rivm.nl/Onderwerpen/L /Leefstijlmonitor. Accessed May 10, 2016.

7. Tiessen-Raaphorst A, van den Dool R. Factsheet. Development of sports participation, club membership and volunteering in sport after 2007 [Factsheet. Ontwikkeling van sportparticipatie, verenigingslidmaatschap en vrijwilligerswerk in de sport na 2007]. The Netherlands Institute for Social Research; 2012. https:// www.scp.nl/dsresource?objectid=d20916c8-7708-4544-93c15943f9a7d68e\&type=org. Accessed June 10, 2015.
8. Van der Klauw M, Verheijden MW, Slinger JD. Report Monitor Covenant Healthy Weight 2013. (Determinants of) exercise-and eating behavior of children (4-11 years, youth (12-17 years) and adults (18+ age) [Rapport Monitor Convenant Gezond Gewicht 2013. (Determinanten van) beweeg- en eetgedrag van kinderen (4-11 jaar), jongeren (12-17 jaar) en volwassenen (18+ jaar)]. Netherlands Organization for Applied Scientific Research; 2013. publications.tno.nl/publication/34617176/.../klauw-2013-monitor.pdf. Accessed June 11, 2015.

9. Reijgersberg N, van der Poel H. Sports participation of children in poverty. Exploration of the literature and interviews about the theme sports participation of children in poverty [Sportdeelname van kinderen in armoede. Verkenning van de literatuur en interviews over het thema sportdeelname van kinderen in armoede]. Mulier Instituut Utrecht. 2014. https://www.kennisbanksportenbewegen.nl/?file=2827 $\& m=1422883252 \&$ action=file.download. Accessed August 11, 2015.

10. Brug J, van Stralen MM, te Velde SJ, et al. Differences in weight status and energy-balance related behaviors among schoolchildren across Europe: the ENERGY-Project. PLoS One. 2012;7:e34742 doi:10.1371/ journal.pone.0034742. PubMed

11. The Netherlands Institute for Social Research. Leisuretime Omnibus [Vrijetijdsomnibus (VTO)]. https://www.scp.nl/Onderzoek/Bronnen/Beknopte_onderzoeksbeschrijvingen/Vrijetijdsomnibus_VTO. Accessed May 10, 2016.

12. Visser K, Tiessen-Raaphorst A. Leisuretime Omnibus [Vrijetijdsomnibus (VTO)]. The Netherlands Institute for Social Research/ Statistics Netherlands. Vrijetijdsomnibus 2014.

13. Postma-de Groot M, Duijvestijn P. A healthy lifestyle in secondary vocational education - current situation [Een gezonde leefstijl in het MBO- stand van zaken. Monitor gezonde leefstijl 2013-2014. Monitor healthy lifestyle 2013-2014]. DSP groep Amsterdam. 2014. http:// www.platformbewegenensport.nl/Document/283/DSP-monitor-Eengezonde-leefstijl-in-het-mbo-2013-2014. Accessed November 12, 2015.

14. Van den Berg, S, Vos, W. Health Survey 2010-2014. Statistics Netherlands.

15. Van den Berg S, Vos W. Lifestyle Monitor in Cooperation With the National Institute for Public Health. Statistics Netherlands; 2014.

16. Dutch Olympic Committee*Dutch Sports Federation. Memberships report 2014 [Ledentallenrapportage 2014]. http://www.nocnsf.nl/ ledentallen. Accessed May 10, 2016.

17. Van Kann DH, Jansen MW, de Vries SI, de Vries NK, Kremers SP. Active Living: development and quasi-experimental evaluation of a school-centered physical activity intervention for primary school children. BMC Public Health. 2015;5:1315. PubMed doi:10.1186/ s12889-015-2633-1

18. Timmermans P, Meinema W, Snel N. Quality of the play environment in the own neighborhood. [Kwaliteit van de speelomgeving in de eigen buurt]. TNS Nipo Amsterdam Jantje Beton Utrecht. 2013. www.jantjebeton.nl/.../Onderzoek-Buitenspelen-2013-TNS-NIPO. pdf. Accessed September 29, 2016.

19. Statistics Netherlands. Lifestyle and (preventive) health research; personal characteristics. http://statline.cbs.nl/Statweb/publication/?DM $=$ SLNL \&PA $=83021 \mathrm{NED} \& \mathrm{D} 1=47,52 \& \mathrm{D} 2=0,5-13,24-25,3741 \& \mathrm{D} 3=$ $0 \& \mathrm{D} 4=1 \& \mathrm{HDR}=\mathrm{T} \& \mathrm{STB}=\mathrm{G} 1, \mathrm{G} 2, \mathrm{G} 3 \& \mathrm{VW}=\mathrm{T}$. Accessed January 12, 2016.

20. Reijgersberg N, van der Werff H, Lucassen J. Baseline Measurement Physical Education [Nulmeting Bewegingsonderwijs]. Mulier Instituut Utrecht. 2013.

21. Reijgersberg N, Lucassen J, Beth J, van der Werff H. Baseline Measurement Physical Education in Secondary School [Nulmeting lichamelijke opvoeding in het voortgezet onderwijs]. Mulier Instituut Utrecht. 2014. 
22. Ministry of Health, Welfare and Sports. National nota health policy. Health near by [Landelijke nota gezondheidsbeleid. Gezondheid dichtbij]. 2011. https://www.rijksoverheid.nl/documenten/kamerstukken/2015/12/04/kamerbrief-over-landelijke-nota-gezondheidsbeleid-2016-2019. Accessed September 29, 2016.

23. World Health Organization European Region; European Commission. Netherlands. Physical Activity Factsheet. 2014. http://www.euro.who. int/_data/assets/pdf_file/0011/288119/NETHERLANDS-PhysicalActivity-Factsheet.pdf?ua=1. Accessed September 29, 2016.

24. Van der Putten H, van Oostrom H, Faber J. Educational agenda Sports, Exercise and a healthy lifestyle in and around school. For, by and with schools 2012-2016 [Onderwijsagenda Sport, Bewegen en een Gezonde Leefstijl in en rondom de school. Voor, door en met de scholen 20122016]. Ministry of Education, Culture and Science, Ministry of Health, Welfare and Sports. 2012. https://www.rijksoverheid.nl/documenten/ rapporten/2012/10/29/onderwijsagenda-sport-bewegen-en-eengezonde-leefstijl-in-en-rondom-de-school. Accessed September 29, 2016.

25. Youth Sports Foundation. Annual Report the Netherlands 2014 [Jaarverslag Jeugdsportfonds Nederland 2014]. Youth Sports Foundation Amsterdam. 2014. http://www.jeugdsportfonds.nl/77/jaarverslag_en_cijfers. Accessed September 29, 2016.

26. Krajicek Foundation. Krajicek Foundation Annual Report 2013 [Krajicek Foundation Jaarverslag 2013]. Krajicek Foundation Den Haag. 2014. http://krajicek.nl/over-ons/jaarverslagen/. Accessed September 29, 2016.

27. Cevaal A, Romijn D. Cruyff Courts Monitor 2012. Mulier Instituut Utrecht. 2012. https://www.kennisbanksportenbewegen.nl/?file=222 $3 \& \mathrm{~m}=1422883076 \&$ action=file. download. Accessed September 29, 2016.

28. Smolenaars N. The first Marc Lammers Plaza in the Netherlands [De eerste Marc Lammers Plaza in Nederland]. Yalp Goor. 2009. http:// www.yalp.nl/toro. Accessed September 29, 2016.

29. Fishman E, Schepers P, Kamphuis CB. Dutch cycling: quantifying the health and related economic benefits. Am J Public Health. 2015;105:13-15. PubMed doi:10.2105/AJPH.2015.302724
30. van Kann DHH, Kremers, SPJ, Gubbels, JS, Bartelink, NHM, de Vries SI, de Vries NK, Jansen MWJ. The association between the physical environment of primary schools and active school transport. Environ Behav. 2014:47:418-435.

31. KpVV CROW. School mobility [School mobiliteit]. http://kpvvdashboard-15.blogspot.nl. Publised September 2013. Assessed May 10, 2016.

32. Slingerland M, Borghouts LB, Hesselink MKC. Physical activity energy expenditure in Dutch adolescents: contribution of active transport to school, physical education and leisure time activities. J Sch Health. 2012;82:225-232. PubMed doi:10.1111/j.17461561.2012.00691.x

33. Snel N. Outside play. Quality of the play enviroment in the own neighborhood. [Buitenspelen. Kwaliteit van de speelomgeving in de eigen buurt]. TNS Nipo Amsterdam Jantje Beton Utrecht. 2011. http://www.jantjebeton.nl/download/Rapport_Buiten_Spelen_JantjeBeton-040311.pdf. Assessed August 27, 2015.

34. Slingerland M, Oomen J, Borghouts L. Physical activity levels during Dutch primary and secondary school physical education. Eur J Sport Sci. 2011;11:249-257. doi:10.1080/17461391.2010.506661

35. Kanters MA, Bocarro JN, Filardo M, Edwards MB, McKenzie TL, Floyd MF. Shared use of school facilities with community organizations and afterschool physical activity program participation: A cost-benefit assessment. J Sch Health. 2014;84:302-309. PubMed doi:10.1111/josh. 12148

36. van Kann DHH, Kremers SPJ, de Vries Si, de Vries NK, Jansen MWJ. Parental Active Transportation Routines (PATRns) as a moderator of the association between neighborhood characteristics and parental influences and active school transportation. Environ Behav. 2015;48(7):946-965.

37. Everything about sports. Hoeveel moet je bewegen volgens de beweegnorm? [How much should you exercise according to the physical activity guideline?] https://www.allesoversport.nl/artikel/hoeveelmoet-je-bewegen-volgens-de-beweegnorm/. Published December 17, 2015, Accessed May 10, 2016. 